\title{
METABOLIC SYNDROME AND CEREBROVASCULAR DISEASE: A CRUCIAL RELATIONSHIP
}

\author{
Ivan Dimitrov
}

\author{
Medical University of Varna
}

Stroke is without any doubt among the top reasons for disability and mortality in neurology. This is especially true in Bulgaria, where vascular diseases in general, and cerebrovascular disease (CVD) in particular, are significantly more prevalent than in other European countries. More than 80 '000 cases of CVD are registered yearly in Bulgaria, over 35'000 having stroke (1). Speaking of stroke, we should not underestimate the other manifestations of CVD, such as transient ischemic attacks and vascular cognitive impairment. The disease may develop silently or cause non-specific complaints for years, and only then become clearly symptomatic. For this reason the diagnosis of CVD can be delayed, which usually leads to less successful prophylaxis and treatment.

Many modifiable risk factors for CVD have been identified. Some key risk factors, including arterial hypertension, insulin resistance or diabetes, obesity, dyslipidemia, have been included in a common definition: metabolic syndrome $(2,3)$. With the advances of basic and clinical research, their significance is growing. However, even with the availability of numerous drugs, arterial hypertension can be hard to control. Obesity has become a global epidemic, so a new term of "globesity" was created, and evidence was gathered that type 2 diabetes mellitus is a disease of the obese people (4). Different criteria for the diagnosis of metabolic syndrome have been proposed. The National Cholesterol Education Program Adult Treatment Panel III (NCEP ATP III) criteria require 3 of the following 5 features to be present: elevated waist circumference (abdominal obesity), elevated triglycerides ( $\geq 1.7 \mathrm{mmol} / \mathrm{L})$, low HDL-C ( $<1.0 \mathrm{mmol} / \mathrm{L}$ in $\mathrm{men}$ and $<1.3 \mathrm{mmol} / \mathrm{L}$ in women), blood pressure $\geq 130 \mathrm{~mm} \mathrm{Hg}$ systolic or $\geq 85 \mathrm{~mm} \mathrm{Hg}$ diastolic, and fasting glucose $\geq 5.6 \mathrm{mmol} / \mathrm{L})(3,5)$. Metabolic syndrome leads to systemic inflammation that activates the coagulation system and may cause the formation of pathological thrombi (6). In a large follow-up study Rodrigues et al. (7) found that persons with either elevated blood pressure or elevated fasting glucose in the clusters to form a metabolic syndrome had the highest risk for incident stroke.

The relationship of metabolic syndrome and cerebrovascular disease and stroke is a topic in this issue of Scripta Scientifica Medica. Dr. Arabadzhieva et al. discuss the problem in two articles, one studying age-related metabolic disturbances (levels of blood glucose and of serum total cholesterol, triglycerides, HDL- and LDL-cholesterol) in adult patients with acute ischemic stroke, and another, dedicated to the disorders of glucose metabolism in a similar group of patients. The authors report commonly elevated blood glucose levels, higher in males than in females, as well as some age and gender differences in the parameters of lipid metabolism in acute ischemic stroke patients. The results of these studies once again accentuate on the importance of metabolic disturbances for CVD, and on the fact that prophylaxis and management of modifiable risk factors can be considered the best approach to reduce the high medical and social burden of this disease.

\section{REFERENCES}

1. Milanov I, Stamenova P.(Eds.) National consensus statement for prophylaxis, diagnosis and treatment of cerebrovascular disease. Balgarska nevrologiya. 2013;14(3 Suppl.1):170-178.

2. Miglani N, Bains K. Interplay between Proteins and Metabolic Syndrome- A Review. Crit Rev Food Sci Nutr. 2015 Jun 5:0. [Epub ahead of print] 
3. Alberti KG, Eckel RH, Grundy SM, Zimmet PZ, Cleeman JI, Donato KA, et al. Harmonizing the metabolic syndrome: a joint interim statement of the International Diabetes Federation Task Force on Epidemiology and Prevention; National Heart, Lung, and Blood Institute; American Heart Association; World Heart Federation; International Atherosclerosis Society; and International Association for the Study of Obesity. Circulation. 2009 Oct 20;120(16):1640-1645.

4. Aloe L, Tonchev A, Fiore M, Chaldakov G. Homo Diabesus: Involvement Of Metabotrophic Fact. Adipobiology. 2013;5:45-49.

5. Third Report of the National Cholesterol Education Program (NCEP) Expert Panel on Detection, Evaluation, and Treatment of High Blood Cholesterol in Adults (Adult Treatment Panel III) final report. Circulation. 2002 Dec 17;106(25):3143-3421.

6. van Rooy MJ, Pretorius E. Metabolic syndrome, platelet activation and the development of transient ischemic attack or thromboembolic stroke. Thromb Res. 2015 Mar;135(3):434-442.

7. Rodriguez-Colon SM, Mo J, Duan Y, Liu J, Caulfield JE, Jin X, et al. Metabolic syndrome clusters and the risk of incident stroke: the atherosclerosis risk in communities (ARIC) study. Stroke. 2009 Jan;40(1):200-205. 